\title{
Transition to Practice Curriculum for General Internal Medicine Physicians: Scoping Review and National Survey
}

Benjamin Thomson ( $\sim$ bthomso5@jh.edu )

Queens University https://orcid.org/0000-0001-6323-3467

Heather O'Halloran

Queens University

Luke Wu

Queens University

Stephen Gauthier

Queens University

David Taylor

Queens University

\section{Research Article}

Keywords: Competency-based medical education, Transition to practice, Medical Education, Independent practice

Posted Date: February 24th, 2022

DOI: https://doi.org/10.21203/rs.3.rs-1288355/v1

License: (9) (1) This work is licensed under a Creative Commons Attribution 4.0 International License. Read Full License 


\section{Abstract}

Background: There remains a paucity of evidence for curricula for the transition to practice (TTP) stage of Competence by Design internal medicine (IM) training programs. Current entrustable professional activities are based on expert consensus rather than robust subspecialty-specific needs assessment.

Methods: A scoping review was completed to identify studies with TTP focus. A national survey was conducted to identify transition experiences for general internal medicine physicians. Results were assessed by grounded theory analysis to identify core topics for TTP curricula.

Results: Neither scoping review nor national survey identified TTP topics related to the CanMEDS Medical Expert role. Scoping Review: 41 relevant studies were identified. Most (97.6\%) were from North America. The most common study types were observational (survey) or curriculum (13/41 31.7\% for each). Only two studies were exclusively in IM, and the most common subspecialty studied was surgical (13/41, 31.7\%). The most common TTP topics were mentorship, billing and coding, practice management, negotiating contract and job, and financial aspects of practice. National Survey: There were 44 respondents, with the majority $(25 / 44,56.8 \%)$ having completed an IM subspecialty fellowship. Most (38/44) completed medical school in Canada, and most were from academic practice settings (33/44, 75.0\%). The most common TTP topics were billing and coding, personal financial planning, practice management, work-life balance and mentorship. Grounded Theory Analysis: There were six themes that encompassed all TTP topics from the scoping review and national survey, being (i) building a career, (ii) continuing professional development, (iii) expectations of the profession, (iv) practice management, (v) Life, health and well-being and (vi) clinical skills. Curriculum competencies and resources for curriculum development were provided.

Conclusions: This study identifies topics critical for curricula development for IM transition to practice. Further research is required to evaluate effectiveness of curricula including topics and themes developed from this scoping review and national survey.

\section{Background}

The Royal College of Physicians and Surgeons of Canada,(1) along with other national medical education authorities, $(2,3)$ have adopted Competency Based Medical Education (CBME) to reform the training of medical specialists. Within Competence by Design (CBD), the Royal College's approach to CBME, postgraduate learners progress through graduated stages of training in preparation for entering unsupervised practice.(4) The final stage of training in CBD, Transition to Practice (TTP), focuses on the challenges graduating residents face when entering unsupervised practice. An effective TTP curriculum should prepare residents to negotiate these challenges ably and to transition smoothly into practice. It follows that fundamental to building an effective TTP curriculum is a clear understanding of the needs that physicians have in this transition. 
Extensive surgical literature describes challenges faced by surgical trainees entering practice.(5-9) However, there is a paucity of literature for internal medicine physicians, making the required curricular components for this stage uncertain. The entrustable professional activities (EPA) adopted and currently used to direct learning and assessment at this stage of residency training are based on expert consensus of clinicians and educators and may not capture the transition needs of internists entering practice.(10) Ensuring a TTP curriculum serves its purpose requires a more robust and specialty-specific needs assessment on which a curriculum can be built.

In constructing a novel Transition to Practice curriculum for the Queen's Internal Medicine residency program, we sought a robust understanding of the transition experience from residency to unsupervised practice. To achieve this, a scoping review was performed to identify the core themes and interventions previously published with a focus on those relevant to an internal medicine TTP curriculum. To determine if the findings of the scoping review were consistent with general internists' transition experiences, a national survey of general internists was conducted. Informed by the scoping review, and validated by the national survey, core TTP topics for a curriculum were identified for residents in internal medicine residency training.

\section{Methods}

\section{Part 1: Scoping Review}

\section{Search strategy and Study Selection Criteria}

A scoping review was conducted using Cochrane, Embase, Pubmed/Medline and Web of Science databases, with no date or language restriction. Search terms included "transition to practice," "competency based medical education," "starting independent practice," "starting practice." Editorials, commentaries and review articles were excluded, but were read to identify additional studies to include in the scoping review.

Studies were included if the study population included either residents or physicians within the first 5 years of unsupervised practice. Observational and interventional trials were included, when the study focus was on transition from supervised to unsupervised practice. Supervised practice was as part of a residency training program, and unsupervised practice was as a licensed practising physician outside of a residency training program. All physician specialties and countries of study were included. Studies that described the transition to practice for health care professionals other than physicians were excluded.

Two authors (BT, LW) screened all titles and abstracts, and two authors (BT, HO) completed full text review, using Covidence systematic review software (Veritas Health Innovation, Melbourne, Australia). Conflicts were resolved by discussion and consensus between both authors.

\section{Data extraction}


All studies were described by study type, country, population, and subspecialty. All interventional studies were further described by the type and outcome of intervention. Topics identified as important to TTP for each study were recorded.

Meta-analysis of data was not possible due to the heterogenous nature of available studies.

\section{Part 2: National Survey}

\section{Survey Creation}

A 9-question survey was created for physicians in unsupervised practice in Canada in internal medicine (IM) (Appendix 1). The overarching reason for the national survey was to deteremine if the scoping review findings were consistent with TTP experiences of a representative cohort of general internists. Survey construction addressed two objectives. Objective 1 was to gather background demographic and training information of survey respondents, to establish the nature of clinical practice and the breadth of representation across the range of IM practices. Objective 2 was to describe survey respondents' perceptions of challenges faced moving into unsupervised practice, and to determine what might have improved that experience. The survey included one open-ended question (objective 2), followed by 8 multiple choice questions (objective 1). The survey was reviewed and completed by two physicians not involved in the research study, to establish face validity.

\section{Participant Identification}

We sampled internal medicine program directors across Canada and then used snowball sampling to identify general internists in community practice. We aimed to include participants representing diverse backgrounds, practice types, years of experience and geography.

\section{Survey Distribution and Data Collection}

The survey was distributed electronically using the online survey tool SurveyMonkey (SurveyMonkey, San Mateo, California, USA). A web link to the survey was emailed to program directors in Canada with a request that the invitation email (and link) be shared with other internal medicine physicians in Canada. The survey opened December 3 (2020) and closed on January 30 (2021). Data was collected anonymously. Survey respondents who did not identify as an internal medicine physician in unsupervised practice were excluded.

\section{Part 3: Grounded theory analysis}

The results of the scoping review and national survey were assessed using using grounded theory and constant comparative method,(11) as previously described.(12) Study topics identified during data extraction of scoping review, and question 1 of the national survey, were collected, and initial codes were generated. Two authors (DT, BT) independently searched the generated codes for themes, then defined and named themes. The two authors (DT, BT) discussed their independently defined and named themes, and created a final list after discussion and consensus. 
Curricular competencies were identified (DT, BT), initially independently, then finalized after discussion and consensus, to reflect all coded topics within themes.

\section{Context of Internal Medicine Residency Training Program}

Queen's University (Kingston, Ontario, Canada) is one of 17 Canadian internal medicine (IM) residency training programs. Each IM training program takes approximately 3 years, and is separated into stages of Competence by Design (CBD), as per the Royal College of Physicians and Surgeons of Canada (RCPSC) version of Competency Based Medical Education (CBME). The CBD stages include, in order, transition to discipline, foundations of discipline, core of discipline, then transition to practice (TTP). Graduates of Queen's University's IM residency training program move into independent practice in a variety of community and academic settings, in urban and rural settings, predominantly throughout Canada.

\section{Ethics}

Ethics approval was not required for this study, since all data was collected anonymously or from previously published sources.

This trial was registered under PROSPERO, Registration number 216352.

\section{Results}

\section{Part 1: Scoping Review}

Database search produced 1502 references (Fig. 1). Removal of duplicates $(n=783)$ yielded 719 titles and abstracts to screen. After irrelevant $(n=628)$ titles and abstracts were removed, there were 91 full text articles for review. There were 50 full text articles excluded on full review, leaving 41 studies that were included in this review. The study summary is included (Supplemental Table 1).

\section{Study Characteristics}

Most studies were performed in North America (40/41)(Table 1). Most (22/41) studies were descriptive, with survey being the most common type $(n=13)$ of descriptive study. The remaining studies $(19 / 41)$ were interventional, and the most common intervention was a curriculum $(n=13)$, followed by elective rotation $(n=2)$.

The study population experience level included residents $(n=21)$, new-to-practice physicians $(n=17)$ or mixed experience level $(n=3)$.

The most common study population subspecialty was surgical $(n=13)$. A small number of studies were from medicine subspecialties $(n=4)$ or general internal medicine $(n=3)$.

Outcome Characteristics 
All included studies identified topics relevant for TTP. Topics relevant to TTP identified from manuscripts in the scoping review Table were summarized (Table 2). The most common topics identified were mentorship $(n=12,29.3 \%)$, billing and coding $(n=12,29.3 \%)$, practice management $(n=11,26.8 \%)$, negotiating for a job or contract $(n=10,24.4 \%)$, and financial aspects of practice $(n=9,22.0 \%)$. There were 37 topics identified in the scoping review, with frequency ranging from 1 to 13 of the manuscripts.

\section{Part 2: National Survey}

\section{Objective 1: Representative Sample of General Internal Medicine Physicians}

Two sets of survey responses were excluded as the respondent was not practicing as a general internal medicine physician. The remaining survey responses $(n=44)$ were included for further analysis $($ Table 3$)$.

The survey respondents came from a diverse educational, professional and clinical backgrounds. Most respondents $(38 / 44,86.4 \%)$ completed medical school in Canada. Respondents completed core internal medicine in British Columbia (8/44), Alberta (1/44), Ontario (30/44), Quebec (2/44) and Nova Scotia (1/44). There were approximately equal numbers of internal medicine practitioners who had (25/44) and hadn't (19/44) completed General Internal Medicine subspecialty training.

There was representation from broad ranges of age, with most respondents between the age of 31-40 $(24 / 44,54.5 \%)$. There was approximately equal representation of internal medicine physicians within the first five years $(17 / 44,38.6 \%)$ and more than 10 years in unsupervised practice (20/44, 45.5\%). Most respondents $(33 / 44,75.0 \%)$ were from academic centers, and there was good representation from community internal medicine practitioners (10/44, 22.7\%).

\section{Objective 2: Topics Important for Transition to Practice}

The national survey identified 22 different topics relevant to TTP (Table 2). The most frequently identified topics were billing and coding $(n=25,56.8 \%)$, personal financial planning $(n=18,40.9 \%)$, practice management $(n=11,25.0 \%)$, work-life balance $(n-=8,18.2 \%)$ and mentorship $(n=7,15.9 \%)$. Most $(19 / 22)$ national Survey TTP topics were also identified in the scoping review. However, the importance of collegiality, deciding between urban and rural job settings, and difficult patient conversations were identified in the national survey but not the scoping review.

\section{Part 3: Grounded Theory analysis}

After discussion and consensus, analysis of the coded topics (Table 2) yielded themes and subthemes (Table 4).

There were six major TTP themes. Building a career included 12 coded topics relevant to mentorship, job application skills, and identification of a desired job. Continuing professional development included 2 coded topics relevant to continuous professional education and understanding professional bodies and membership groups. Expectations of the profession included 10 coded topics and was subcategorized 
into medicolegal issues, professional conduct, qualify improvement in practice, and the teaching or supervisory role. Practice management included 5 coded topics related to practice finances and a strategy for learning in transition to practice. Life, Health and Well-being included 3 coded topics related to personal finances and health and well-being. Clinical skills included 9 coded topics related to communication to colleagues and patients, conflict resolution, signovers, and understanding the function of members of the multidisciplinary team.

\section{Agreement between Scoping Review and National Survey}

The majority $(19 / 22,86.4 \%)$ of topics identified in the national survey were also identified in the scoping review. Three topics were unique to the national survey (difficult patient conversations, urban versus rural job settings, collegiality) but each was identified only once. There was significant overlap in the most commonly identified topics in the scoping review and national survey, with mentorship (29.3 vs $15.9 \%$ ), billing and coding (29.3 vs $56.8 \%$ ), practice management ( 26.0 vs $25.0 \%$ ), negotiating contract and job (24.4 vs $13.6 \%$ ) and personal financial planning (17.1 vs $40.9 \%)$. There were 18 topics unique to the scoping review, but the majority $(12 / 18,66.7 \%)$ were identified in only one study.

\section{Discussion}

There remains a paucity of literature evaluating internal medicine physicians' transition to practice within the CBD framework. There are several reasons why medical educators may have overlooked the importance of this transition. Physicians value independent decision-making as a critical part of the medical profession,(13) so transition interventions may be perceived as being overly obtrusive or paternalistic. Similarly, many faculty members successfully transitioned into unsupervised practice when support or guidance may not have been offered, and may thus feel that residents could similarly advance with minimal guidance.(14) However, there is good evidence that residents entering unsupervised practice feel unprepared,(15) that their personal relationships and quality of life suffer, and that this lack of preparation leads some physicians to leave the profession.(16-18) Thus, it remains critical to improve residents' transition to unsupervised practice.

No manuscript identified in the scoping review, and no response to the national survey suggested that additional time should be spent furthering medical knowledge during the TTP stage of residency training. Using the CanMEDS framework,(19) the Medical Expert role appears to be well taught in internal medicine programs and assessed on certification examinations. Residents nearing the end of training in Canada and the United States consistently feel confident in their clinical knowledge.(20-24) While this may reflect the Dunning-Kruger effect,(25) the earlier CBD stages of Foundations of Training and Core of Discipline largely focus on building their clinical medical expertise. In contrast, the scoping review and National survey identified other CanMEDS roles as needing increased focus for Transition to Practice.

Personal financial planning was frequently identified in the scoping review $(17.1 \%)$ and national survey (40.9\%). Residents commonly are burdened by high levels of debt, which can influence decisions about career direction.(26) Debt associates with poor quality of life, burnout, and medical errors, while also 
delaying decisions on having children or purchasing a house. $(27,28)$ Furthermore, there remains minimal study in how to overcome racial and gender disparities in physician career progression and pay. $(29,30)$ It is thus understandable that this topic is of such importance to physicians when entering unsupervised practice. A Practice Management Seminar was evaluated in Psychiatry residents that involved talks from a financial analyst regarding concepts of return on investment and reimbursement policies. This seminar series was highly rated by participants and may be one mechanism to teach this important TTP topic. Based on the national surveys, personal financial planning education should also cover debt management, life and disability insurance, and the benefits of incorporation. Meeting individually with a financial analyst may have the benefit of personalizing the information with development of a long-term personal financial plan.

Understanding the financial aspects of practice was commonly identified in the scoping review. There are several components to this, including billing and coding, understanding payment or salary systems, as well as the financial components of office management. Formal business training is not commonly incorporated into residency training, leaving most young physicians feeling unprepared to manage the business aspects of practice.(31) The lack of formal business acumen has been described in internal medicine, psychiatry, surgery and anesthesiology,(32-35) and despite wide spread recognition of its importance, program directors agree that trainees remain insufficiently trained in the topic.(36) Business of medicine courses have been widely implemented into obstetrics and gynecology,(37) ophthalmology, (38) surgery,(39) psychiatry,(40) pediatrics,(41) radiology,(42) and internal medicine.(43, 44) Active learning methodologies appear more effective than didactic teaching in family medicine trainees.(45) Further study is thus required to identify the optimal mechanism of delivering this knowledge for internal medicine physicians.

Mentorship is associated with improved patient care and safety, improved physician confidence, job satisfaction, and decreased burnout.(46-49) However, mentorship was the most commonly identified TTP topic in our scoping review $(29.3 \%)$ and was also commonly identified from the national survey (15.9\%). It is likely that a long-term mentor could address many topics identified in this study, including finding jobs, medicolegal issues, leadership skills, building a curriculum vitae, improving communication with colleagues, finding resources for transition to practice, the importance of collegiality, and improving understanding of hospital or health care system guidelines or policies. Unfortunately, the lack of formal mentorship remains a limitation in many training programs. There are many reported reasons for this, including limited time,(50) perceived competition from or financial costs to mentors,(51) and the inability to match race and gender of mentor and mentee.(52) Given the certainty of the mentee benefits, further study is essential to identify how best to incorporate mentorship programs within internal medicine TTP curricula.

Grounded theory analysis provides direction towards the development and evaluation of internal medicine TTP curricula. Three manuscripts in the scoping review described interventions that included internal medicine residents or physicians. In MacMillan et al,(53) general internal medicine fellowship graduates were part of a journal club for the purpose of peer mentorship. At each journal club session, a 
TTP topic was raised such as billing, job negotiations and developing a CV. Relevant TTP topics were identified by an analysis of the sessions. Unfortunately, there was no evaluation of the sessions by attendees, nor was it compared to an alternative method of delivery TTP curricula. In Kleinschmidt et al, (54) a TTP curriculum was provided during a 2 week clinical service to internal medicine residents in a USA academic center. Curriculum topics were determined by a survey of an unreported number of recent graduates of the same internal medicine program. Resident participants reported improved abilities in 5 of the 6 areas of focus of the curriculum (leading a team, in-basket management, chronic disease management strategies, providing efficient acute care, and billing/coding). Unfortunately, this study was published as a pilot trial of only four residents in a single center, and thus may not be generalizable. In Gephart et al,(55) a trial practice management curriculum was provided in a one-day series of workshops, to resident trainees, focusing on debt repayment, billing compliance, medical malpractice, contract negotiations, lifestyle and financial management. A pre- and post-attendance survey confirmed improved confidence in one topic area (contract negotiations). Unfortunately, the rationale for the chosen topic focus was not stated, and trainees from 20 different specialties were included. The findings are thus not likely generalizable to internal medicine residents, and the relevance of the topics of curriculum focus is uncertain. There were limited studies reporting internal medicine or internal medicine subspecialties TTP, but the findings of the national survey of practicing general internists was consistent to the scoping review findings of a broader range of specialties. That said, there remains a paucity of research on curriculum interventions for TTP for internal medicine training programs.

This study's combination of scoping review and national survey yields the most comprehensive list of internal medicine TTP topics for curriculum design. Covering the spectrum of the CanMEDS roles that surround Medical Expert, the analysis is a framework to design a curriculum that confronts each of the challenges internal medicine physicians face when entering unsupervised practice. Resources are freely available for several of the TTP topics identified in our study (Supplementary Table 2). A study is ongoing at our center to develop and to evaluate a curriculum that utilizes many of these resources. It remains essential that such studies are published, regardless of whether positive or negative results are produced.

This study has several notable strengths. Firstly, the combination of a scoping review and national survey led to a comprehensive list of TTP topics for internal medicine physicians. The organization of these topics into themes provides a template for curriculum design and evaluation. Secondly, the scoping review identified high yield TTP topics from areas outside but still relevant to internal medicine, while the inclusion of the majority of these topics was subsequently validated by being identified in a national survey of highly representative internal medicine physicians. Thirdly, the analysis is coupled with curricular competencies, permitting simpler evaluation of a TTP curriculum intervention in a CBME learning environment. There are also weaknesses to this study. Firstly, the majority of the national survey respondents identified as being in academic settings, so the TTP topics may be less generalizable to community settings. A response rate could not be quantitated due to the non-discriminative sampling method. However, demographic data did confirm that the respondents were inclusive of a broad spectrum of practicing general internists. Secondly, it is possible that the TTP experiences of general internists in the early part of their career are more relevant. However, this study did not restrict participation depending 
on timing of independent practice, as authors preferred to be overinclusive in topic identification. This strategy was validated by the high level of agreement between the scoping review and national survey identified topics. Thirdly, this study was unable to identify the effect of sex, race and socioeconomic background on the unique TTP challenges faced by internal medicine physicians. While this was not the objective of this study, these factors have a pronounced impact on several TTP topics such as mentorship, negotiation of jobs, and personal financial planning. It is essential that design and evaluation of TTP curricula consider these factors. Fourthly, this study a priori limited study to the transition to independent practice experiences of physician health care professionals only. It is possible that inclusion of nursing or other non-physician health care professionals would have increased the breadth of the study findings. Finally, this study did not report a TTP curriculum, but rather the important topics to be included. While a curricula has been developed, it is not yet evaluated and thus it would be premature to report. However, the value of this study is reporting the topics that should be included in a TTP curriculum; it is the authors' hope that this work precipitates multiple curricula that will be evaluated and reported.

\section{Conclusions}

This study identifies topics critical for development of a curriculum for internal medicine transition to practice. Further research is required to evaluate the effectiveness of curricula that include topics and themes developed from this scoping review and national survey.

\section{List Of Abbreviations}

CBD Competency by Design

CBME Competency Based Medical Education

CMPA Canada Medical Protective Association

EPA Entrustable Professional Activities

IM Internal Medicine

TTP Transition to Practice

USA United States of America

\section{Declarations}

Ethics approval and consent to participate: Ethics approval was not required for this study, since all data was collected anonymously or from previously published sources. This trial was registered under PROSPERO, Registration number 216352. 
Consent for publication: All authors have consented for publication.

Availability of data and material: All data is available on request of the corresponding author.

Competing interests: None

Funding: None

Authors contributions: BT was involved in study conceptualization, methodology, data collection and analysis, writing original draft, and reviewing and editing all subsequent drafts. $\mathrm{HOH}$ and LW were involved in study methodology, data collection and analysis, and reviewing and editing all subsequent drafts. SG was involved in study methodology, data analysis, and reviewing and editing all subsequent drafts. DT was involved in study conceptualization, methodology, data analysis, writing original draft, and reviewing and editing all subsequent drafts. All authors approve of the final version.

Acknowledgements: None

\section{References}

1. Harris KA, Nousiainen MT, Reznick R. Competency-based resident education-The Canadian perspective. Surgery. 2020;167(4):681-4.

2. Lindeman B, Sarosi GA. Competency-based resident education: The United States perspective. Surgery. 2020;167(5):777-81.

3. Olopade FE, Adaramoye OA, Raji Y, Fasola AO, Olapade-Olaopa EO. Developing a competency-based medical education curriculum for the core basic medical sciences in an African Medical School. Adv Med Educ Pract. 2016;7:389-98.

4. Canada RCoPaSo. Getting started: What is CBD? 2020 [Stages of training: Competence Continuum diagram]. Available from: https://www.royalcollege.ca/rcsite/documents/cbd/full-meantime-guide-e.

5. Bell RH Jr, Biester TW, Tabuenca A, Rhodes RS, Cofer JB, Britt LD, et al. Operative experience of residents in US general surgery programs: a gap between expectation and experience. Ann Surg. 2009;249(5):719-24.

6. Coleman JJ, Esposito TJ, Rozycki GS, Feliciano DV. Early subspecialization and perceived competence in surgical training: are residents ready? J Am Coll Surg. 2013;216(4):764-71. discussion $71-3$.

7. George BC, Bohnen JD, Williams RG, Meyerson SL, Schuller MC, Clark MJ, et al. Readiness of US General Surgery Residents for Independent Practice. Ann Surg. 2017;266(4):582-94.

8. Mattar SG, Alseidi AA, Jones DB, Jeyarajah DR, Swanstrom LL, Aye RW, et al. General surgery residency inadequately prepares trainees for fellowship: results of a survey of fellowship program directors. Ann Surg. 2013;258(3):440-9. 
9. Teman NR, Gauger PG, Mullan PB, Tarpley JL, Minter RM. Entrustment of general surgery residents in the operating room: factors contributing to provision of resident autonomy. J Am Coll Surg. 2014;219(4):778-87.

10. Taylor DR, Park YS, Smith CA, Karpinski J, Coke W, Tekian A. Creating Entrustable Professional Activities to Assess Internal Medicine Residents in Training: A Mixed-Methods Approach. Ann Intern Med. 2018;168(10):724-9.

11. Kolb SM. Grounded Theory and the Constant Comparative Method: Valid Research Strategies for Educators. J Emerg Trends Educational Res Policy Stud. 2012;3(1):83-6.

12. Nowell L, Norris JM, White DE, Moules NJ. Thematic Analysis: Striving to Meet the Trustworthiness Criteria. International Journal of Qualititative Methods. 2017;16(1).

13. Cochrane C. Successful Medical Trainees and Practitioners. In: C.E.Vincent RHCa, editor. Psychosocial Aspects of Medical Training. Springfield, Illinois1971. p. 168 - 90.

14. Borus JF. The Transition to Practice. J Med Educ. 1982;57(8):593-601.

15. Best LR, Sengupta A, Murphy RJL, de Metz C, Trotter T, Loewen SK, et al. Transition to practice in radiation oncology: Mind the gap. Radiother Oncol. 2019;138:126-31.

16. Cogbill TH, Shapiro SB. Transition from Training to Surgical Practice. Surg Clin North Am. 2016;96(1):25-33.

17. Donahue CA, Kuhnen AH, Kleiman DA, Marcello PW, Schoetz DJ Jr, Roberts PL, et al. How to Get Ahead: Early-Career Colorectal Surgeons Reflect on Their First Few Years in Practice. J Surg Educ. 2020.

18. Sanaee L, Nayer M, Takahashi SG. Practical solutions for implementation of Transition to Practice curricula in a competency-based medical education model. Can Med Educ J. 2020;11(4):e39-50.

19. Frank JR, Danoff D. The CanMEDS initiative: implementing an outcomes-based framework of physician competencies. Med Teach. 2007;29(7):642-7.

20. Dijkstra IS, Pols J, Remmelts P, Rietzschel EF, Cohen-Schotanus J, Brand PL. How educational innovations and attention to competencies in postgraduate medical education relate to preparedness for practice: the key role of the learning environment. Perspect Med Educ. 2015;4(6):300-7.

21. McDonnell PJ, Kirwan TJ, Brinton GS, Golnik KC, Melendez RF, Parke DW. 2nd, et al. Perceptions of recent ophthalmology residency graduates regarding preparation for practice. Ophthalmology. 2007;114(2):387-91.

22. Morrow G, Illing J, Redfern N, Burford B, Kergon C. Are specialist registrars fully prepared for the role of consultant? Clin Teach. 2009;6:87-90.

23. brown JM, Ryland I, Shaw NJ, Graham DR. Working as a newly appointed consultant: A study into the transition from specialist registrar. Br J Hosp Med (Lond). 2009;70(7):410-4.

24. Lynch DC, Pugno P, Beebe DK, Cullison SW, Lin JJ. Family practice graduate preparedness in the six ACGME competency areas: prequel. Fam Med. 2003;35(5):324-9. 
25. Dunning D, Johnson D. J E. Why people fail to recognize their own incompetence. Curr Dir Psychol Sci. 2003;12:83-7.

26. Mahajan A, Cahill C, Scharf E, Gupta S, Ahrens S, Joe E, et al. Neurology residency training in 2017: A survey of preparation, perspectives, and plans. Neurology. 2019;92(2):76-83.

27. West CP, Shanafelt TD, Kolars JC. Quality of life, burnout, educational debt, and medical knowledge among internal medicine residents. JAMA. 2011;306(9):952-60.

28. Rohlfing J, Navarro R, Maniya OZ, Hughes BD, Rogalsky DK. Medical student debt and major life choices other than specialty. Med Educ Online. 2014;19:25603.

29. Sterbling HM, Molena D, Rao SR, Stein SL, Litle VR. Initial report on young cardiothoracic surgeons' first job: From searching to securing and the gaps in between. J Thorac Cardiovasc Surg. 2019;158(2):632-41. e3.

30. Sanfey H, Crandall M, Shaughnessy E, Stein SL, Cochran A, Parangi S, et al. Strategies for Identifying and Closing the Gender Salary Gap in Surgery. J Am Coll Surg. 2017;225(2):333-8.

31. Cantor JC, Baker LC, Hughes RG. Preparedness for practice. Young physicians' views of their professional education. JAMA. 1993;270(9):1035-40.

32. Holak EJ, Kaslow O, Pagel PS. Facilitating the transition to practice: a weekend retreat curriculum for business-of-medicine education of United States anesthesiology residents. J Anesth. 2010;24(5):807-10.

33. Williams LL. Teaching residents practice-management knowledge and skills: an in vivo experience. Acad Psychiatry. 2009;33(2):135-8.

34. Adiga K, Buss M, Beasley BW. Perceived, actual, and desired knowledge regarding Medicare billing and reimbursement. A national needs assessment survey of internal medicine residents. J Gen Intern Med. 2006;21(5):466-70.

35. Stubbe DE. Preparation for practice: child and adolescent psychiatry graduates' assessment of training experiences. J Am Acad Child Adolesc Psychiatry. 2002;41(2):131-9.

36. Lusco VC, Martinez SA, Polk HC. Jr. Program directors in surgery agree that residents should be formally trained in business and practice management. Am J Surg. 2005;189(1):11-3.

37. Williford LE, Ling FW, Summitt RL Jr, Stovall TG. Practice management in obstetrics and gynecology residency curriculum. Obstet Gynecol. 1999;94(3):476-9.

38. Tsai JC, Lee PP, Chasteen S, Taylor RJ, Brennan MW, Schmidt GE. Resident physician mentoring program in ophthalmology: the Tennessee experience. Arch Ophthalmol. 2006;124(2):264-7.

39. Gill JB, Schutt RC. Jr. Practice management education in orthopaedic surgical residencies. J Bone Joint Surg Am. 2007;89(1):216-9.

40. Wichman CL, Netzel PJ, Menaker R. Preparing psychiatric residents for the "real world": a practice management curriculum. Acad Psychiatry. 2009;33(2):131-4.

41. Babitch LA. Teaching practice management skills to pediatric residents. Clin Pediatr (Phila). 2006;45(9):846-9. 
42. Chan S. Management education during radiology residency: development of an educational practice. Acad Radiol. 2004;11(11):1308-17.

43. David RA, Reich LM. The creation and evaluation of a systems-based practice/managed care curriculum in a primary care internal medicine residency program. Mt Sinai J Med. 2005;72(5):2969.

44. Crites GE, Schuster RJ. A preliminary report of an educational intervention in practice management. BMC Med Educ. 2004;4:15.

45. Bayard M, Peeples CR, Holt J, David DJ. An interactive approach to teaching practice management to family practice residents. Fam Med. 2003;35(9):622-4.

46. Yardley S, Westerman M, Bartlett M, Walton JM, Smith J, Peile E. The do's, don't and don't knows of supporting transition to more independent practice. Perspect Med Educ. 2018;7(1):8-22.

47. Higgins R, Gallen D, Whiteman S. Meeting the non-clinical education and training needs of new consultants. Postgrad Med J. 2005;81(958):519-23.

48. Sachdeva AK, Flynn TC, Brigham TP, Dacey RG Jr, Napolitano LM, Bass BL, et al. Interventions to address challenges associated with the transition from residency training to independent surgical practice. Surgery. 2014;155(5):867-82.

49. Griffin A, Abouharb T, Etherington C, Bandura T. Transitional to independent practice: a national enquiry into the educational support for newly qualified GPs. Educ Prim Care. 2010;21:299-307.

50. Ecomopoulos K, Sun R, Garvey E, Ba'zzarelli A. Coaching and mentoring modern surgeons. Bull Am Coll Surg. 2014;99:30-5.

51. Straus SE, Chatur F, Taylor M. Issues in the mentor-mentee relationship in academic medicine: A qualitative study. Acad Med. 2009;2009(84):135-9.

52. Fang D, Moy E, Colburn L, Hurley J. Racial and ethnic disparities in faculty promotion in academic medicine. JAMA. 2000;284:1085-92.

53. MacMillan TE, Rawal S, Cram P, Liu J. A journal club for peer mentorship: helping to navigate the transition to independent practice. Perspect Med Educ. 2016;5(5):312-5.

54. Kleinschmidt P, Addington-White J, Feldstein DA, Abraham V, Baier L. Increasing Senior Resident Readiness to Practice in Primary Care. J Gen Intern Med. 2018;33:712-S3.

55. Gephart MH, Schaffer R, Katznelson L, Piro N. Transition-to-Practice Curriculum in Graduate Medical Education. J Neurosurg. 2017;126(4):A1398-A.

56. Aboulioud M, Hirose R, Nagai S, Gordon C, Farmer D. Surgeon Readiness for Entry Into Practice: A Survey of Abdominal Transplant Surgeons in the United States. Am J Transplant. 2019;19 (suppl 3).

57. Arno KL, Hock S. Senior Resident "Simtending" Curriculum: Novel Simulation-Based Transition to Practice. Acad Emerg Med. 2020;27(S1):321.

58. Caretta-Weyer H. Transition to Practice: A Novel Life Skills Curriculum for Emergency Medicine Residents. Western J Emerg Med. 2019;20(1):100-4. 
59. Chan M, van Manen MA. Exploring the transition into practice of general paediatricians from a Canadian residency program. Paediatr Child Health. 2018;23(5):314-8.

60. Chu D, Vaporciyan AA, lannettoni MD, Ikonomidis JS, Odell DD, Shemin RJ, et al. Are There Gaps in Current Thoracic Surgery Residency Training Programs? Ann Thorac Surg. 2016;101(6):2350-6.

61. Cooper L, Sinclair D, Cobas M, Freytag A, Grossman J. Transition to Practice: A New Paradigm in Anesthesiology Resident Training. Anesth Analg. 2010;110(3):201.

62. Cooper L, Sinclair D, Cobas M, Freytag A, Grossman J, Manning R. Transition-to-practice: New Training Paradigm Improves Resident Performance of Practice Management Skills. Anesth Analg. 2010;110(3):216.

63. Cyr CE, Cyr MM, Quirt J, Connors L. Transition to practice: lessons learned in allergy and immunology training. Allergy Asthma and Clinical Immunology. 2021;17(S1):17.

64. Daniels AH, McDonnell M, Born CT, Hayda RA, Ehrlich MG, T PG, et al. Critical Analysis of a Trauma Fellowship-Modeled, Six-Year Orthopedic Surgery Training Program. J Bone Joint Surgery-American Volume. 2013;95(15):e108. 1) - e (8).

65. de Montbrun S, Patel P, Mobilio MH, Moulton CA. Am. I Cut Out for This? Transitioning from Surgical Trainee to Attending. Journal of Surgical Education. 2017;75(3):606-12.

66. Harris AO, Delany C. International medical graduates in transition. Clin Teach. 2013;10:328-32.

67. Huynh C, Wong-Chong N, Vourtzoumis P, Lim S, Marini W, Johal G, et al. The future of general surgery training: A Canadian resident nationwide Delphi consensus statement. Surgery. 2019;166(5):726-34.

68. Kelly M, Posa M. Transition to Pediatric Practice: A Residency Elective Experience to Prepare Senior Pediatric Residents for General Pediatric Primary Care. MedEdPORTAL. 2016;12:10506.

69. Kilbertus S, Pardhan K, Zaheer J, Bandiera G. Transition to practice: Evaluating the need for formal training in supervision and assessment among senior emergency medicine residents and new to practice emergency physicians. Can J Emerg Med. 2019;21(3):418-26.

70. Koo K, Bowman MS, Ficko Z, Gormley EA. Older and wiser? Changes in unprofessional content on urologists' social media after transition from residency to practice. BJU Int. 2018;122(2):337-43.

71. Kuza CM, Harbell MW, Malinzak EB, Goff KL, Bicket MC, Ifeanyi-Pillette IC, et al. Transition to Practice in Anesthesiology: Survey Results of Practicing Anesthesiologists on Their Experience. J Educ Perioper Med. 2019;21(2):E619.

72. Lister JR, Friedman WA, Murad GJ, Dow J, Lombard GJ. Evaluation of a Transition to Practice Program for Neurosurgery Residents: Creating a Safe Transition From Resident to Independent Practitioner. Journal of Graduate Medical Education. 2010;September:366 - 72.

73. Miracle C, Vargas ER, Mullaney S, Nangia S, Makadia PM. Nephrology business leadership university: Filling a gap in fellowship education. J Am Soc Nephrol. 2018;29:65-S.

74. Murad GLJ, Friedman WA, Lombard G. Enhncing Competence in Graduates Through a Transition to Practice Program in Neurological Surgery: 907. Neurosurgery. 2009. 
75. Nath A, Cheung WJ, Leppard J, Perry JJ. A novel transition to practice curriculum for CCFP(EM) programs. Can J Emerg Med. 2021;23(3):394-7.

76. Ovadia SA, Gishen K, Desai U, Garcia AM, Thaller SR. Education on the Business of Plastic Surgery During Training: A Survey of Plastic Surgery Residents. Aesthetic Plast Surg. 2018;42(3):886-90.

77. Patel RRK, Barone J, Elsamra SE. Business education for residents: Results of a Pilot Business Course at a Urology Residency Program. Urol Pract. 2018;5(2):107-11.

78. Rowan-Legg A. Canadian Early Career Paediatricians on their Transition to Practice Experience. Paediatr Child Health. 2018;23(S1):e57-e8.

79. Schrewe B, Patel R, Rowan-Legg A. Growth curves: The experiences of Canadian paediatricians in their first 5 years of independent practice. Paediatr Child Health. 2020;25(4):235-40.

80. Shortt SED, Hodgetts PG. A curriculum for the times: an experiment in teaching health policy to residents in family medicine. Can Med Assoc J. 1997;157:1567-9.

81. Sockalingam S, Wiljer D, Yufe S, Knox MK, Fefergrad M, Silver I, et al. The Relationship Between Academic Motivation and Lifelong Learning During Residency: A Study of Psychiatry Residents. Acad Med. 2016;91(10):1423-30.

82. Sterbling HM, Molena D, Rao SR, Stein SL, Litle VR. Initial report on young cardiothoracic surgeons' first job: From searching to securing adn the gaps in between. The Journal of Thoracic and Cardiovascular Surgery. 2019;August(632-639).

83. Stolarski A, He K, Sell N, Chugh P, O'Neal P, Smink DS, et al. Mentoring experience of new surgeons during their transition to independent practice: A nationwide survey. Surgery. 2021;169(6):1354-60.

84. Stratton J, Matheson K, Davidson S. Transition to Practice Workshop: A Novel Interactive Intervention to Improve Resident Education. J Am Acad Child Adolesc Psychiatry. 2018;57(10):197-S.

85. Patel Y, Yen C, Tsai M, Kelbert J, Easdowne J, Macario A. A four week or management rotation utilizing a cRNA-based evaluation tool. Anesth Analg. 2012;114(5 Supplement 1):204.

86. Velazco CS, Davila VJ, Alhajjat AM, Ostlie DJ, Garvey EM. Mentorship in pediatric surgery: A need for structure? J Pediatr Surg. 2021;56(5):892-9.

87. Vetere P, Cooke S. Preparedness to practice paediatric hospital medicine. Paediatr Child Health. 2020;25(7):447-54.

88. Witherspoon L, Jalali S, Roberts MT. Resident-run urology clinics: A tool for use in competency-based medical education for teaching and assessing transition-to-practice skills. Cuaj-Canadian Urol Association J. 2019;13(9):E279-E84.

\section{Tables}


Table 1: Details of Studies from Scoping Review

\begin{tabular}{|c|c|}
\hline Study Characteristic & $N(\%)$ \\
\hline \multicolumn{2}{|l|}{ Country } \\
\hline United States & $25(61.0)$ \\
\hline Canada & $15(36.6)$ \\
\hline Australia & $1(2.4)$ \\
\hline \multicolumn{2}{|l|}{ Study Type } \\
\hline Descriptive: & $13(31.7)$ \\
\hline Interview & $6(14.6)$ \\
\hline Meetings & $1(2.4)$ \\
\hline Review of social media posts & $1(2.4)$ \\
\hline Moderated focus groups & $1(2.4)$ \\
\hline Interventional: & $13(31)$. \\
\hline Elective rotation & $2(4.9)$ \\
\hline Workshop & $1(2.4)$ \\
\hline Journal club with discussion groups & $1(2.4)$ \\
\hline Resident run clinic & $1(2.4)$ \\
\hline Transition to practice year & $1(2.4)$ \\
\hline \multicolumn{2}{|l|}{ Study Population - experience } \\
\hline Residents & $21(51.2)$ \\
\hline New-to-practice physicians & $17(41.5)$ \\
\hline Both residents and new-to-practice physicians & $3(7.3)$ \\
\hline \multicolumn{2}{|l|}{ Study Population - subspecialty } \\
\hline Surgical subspecialties & $13(31.7)$ \\
\hline Pediatrics & $6(14.6)$ \\
\hline Emergency medicine & $4(9.8)$ \\
\hline Anesthesiology & $4(9.8)$ \\
\hline Medicine subspecialties & $4(9.8)$ \\
\hline Psychiatry & $3(7.3)$ \\
\hline
\end{tabular}


Not specified

Internal Medicine

Family medicine

Radiation oncology
$3(7.3)$

2 (4.9)

1 (2.4)

1 (2.4) 
Table 2: Coded Transition to Practice topics from Scoping Review and National Survey

\begin{tabular}{|c|c|c|}
\hline & Scoping Review & National Survey \\
\hline Coded data & Count (\%) & Count (\%) \\
\hline 1.Mentorship & $12(29.3)$ & $7(15.9)$ \\
\hline 2. Billing and coding & $12(29.3)$ & $25(56.8)$ \\
\hline 3. Practice management & $11(26.8)$ & $11(25.0)$ \\
\hline 4. Negotiating contract and job & $10(24.4)$ & $6(13.6)$ \\
\hline 5. Personal financial planning & $7(17.1)$ & $18(40.9)$ \\
\hline 6. Finding jobs & $6(14.6)$ & $5(11.4)$ \\
\hline 7. Work-life balance & $5(12.2)$ & $8(18.2)$ \\
\hline 8. Local hospital/health system guidelines/policies & $5(12.2)$ & $5(11.4)$ \\
\hline 9. Increased autonomy during residency & $4(9.8)$ & $2(4.5)$ \\
\hline 10. Medicolegal issues & $4(9.8)$ & $2(4.5)$ \\
\hline 11. Teaching Learners & $3(7.3)$ & $1(2.3)$ \\
\hline 12. Documentation & $3(7.3)$ & $1(2.3)$ \\
\hline 13. Insurance (personal health/life/disability) & $3(7.3)$ & $1(2.3)$ \\
\hline 14. Leadership skills & $3(7.3)$ & $1(2.3)$ \\
\hline 15. Outpatient management & $1(2.4)$ & $5(11.4)$ \\
\hline 16. Payment/salary systems & $1(2.4)$ & $2(4.5)$ \\
\hline 17. Building a CV & $2(4.9)$ & $2(4.5)$ \\
\hline 18. Effective communication with colleagues & $1(2.4)$ & $1(2.3)$ \\
\hline 19. Continuous Professional Education & $1(2.4)$ & $1(2.3)$ \\
\hline 20. Financial aspects of practice & $9(22.0)$ & $0(0.0)$ \\
\hline 21. Collaboration with Multidisciplinary team & $6(14.6)$ & $0(0.0)$ \\
\hline 22. Interviewing & $4(9.8)$ & $0(0.0)$ \\
\hline 23. Making a CV or cover letter & $3(7.3)$ & $0(0.0)$ \\
\hline 24. Resources for transition to practice & $2(4.9)$ & $0(0.0)$ \\
\hline 25. Quality Assurance & $2(4.9)$ & $0(0.0)$ \\
\hline
\end{tabular}


26. Presenting to public

27. Advocacy

28. Outpatient resources

29. Social media-Professionalism

30. Handovers

31. Conflict resolution

32. Breaking bad news

33. Reporting obligations

34. Difficult family management

35. Informed consent

36. Choosing between academic versus community

37. Setting up community services for patients

38. Difficult Patient conversations

39. Urban versus rural job settings

40. Collegiality
$1(2.4)$

$1(2.4)$

$1(2.4)$

1 (2.4)

1 (2.4)

1 (2.4)

1 (2.4)

1 (2.4)

1 (2.4)

1 (2.4)

1 (2.4)

$0(0.0)$

1 (2.4)

$0(0.0)$

0 (0.0)

1 (2.3)

0 (0.0)

1 (2.3)

$0(0.0)$

1 (2.3) 
Table 3: National Survey of General Internal Medicine Physicians about Transition to Practice

\section{Respondent Factor}

Subspecialty of

Practice

Educational

Background

\section{Description}

General Internal Medicine

Subspecialty in GIM

No

Yes

Canada

Outside Canada and

USA

USA

Medical School location
Core internal medicine residency location

Canada - Ontario

Canada- British

Columbia

Canada - Quebec

USA

Canada - Nova Scotia

Canada - Alberta

26-30

Age

Professional

Experience

\begin{tabular}{lll} 
& $\begin{array}{l}\text { Canada- British } \\
\text { Columbia }\end{array}$ & $8(18.2)$ \\
& Canada - Quebec & $2(4.5)$ \\
& USA & $2(4.5)$ \\
& Canada - Nova Scotia & $1(2.3)$ \\
\hline Age & Canada - Alberta & $1(2.3)$ \\
\hline & $26-30$ & $2(4.5)$ \\
& $31-35$ & $13(29.5)$ \\
\hline & $36-40$ & $11(25.0)$ \\
\hline & Greater than 40 & $18(40.9)$ \\
\hline & & $17(38.6)$ \\
\hline & $0-5$ & $7(15.9)$ \\
\hline & $6-10$ & $20(45.5)$ \\
\hline & Greater than 10 & $33(75.0)$ \\
\hline
\end{tabular}

Clinical settings

Academic

38 (86.4)

$5(11.4)$

$1(2.3)$

$30(68.2)$

$8(18.2)$

$2(4.5)$

(4.5)

(2.3)

(2.3)

N (\%)

(100.0)

25(56.8)

$9(43.2)$

Experience 
Page 22/26 
Table 4: Coded Transition to Practice Topics from Scoping Review and National Survey

\section{THEME SUB-THEME CODE CURRICULAR COMPETENCIES (Table \\ 2)}

\begin{tabular}{llcl}
$\begin{array}{l}\text { Building a } \\
\text { Career }\end{array}$ & Career mentorship & 1,17 & $\begin{array}{l}\text { Develop a career plan for promotions and career } \\
\text { building }\end{array}$ \\
\hline Career mentorship & 1,8 & $\begin{array}{l}\text { Learn the policies and protocols for the hospital } \\
\text { and health system }\end{array}$ \\
\hline Career mentorship & 14 & $\begin{array}{l}\text { Identify leadership opportunities and develop a } \\
\text { personal leadership plan }\end{array}$ \\
\hline
\end{tabular}

\begin{tabular}{|c|c|c|c|}
\hline & Job application skills & 23 & Create a personal curriculum vitae and cover letter \\
\hline & Job application skills & 22 & $\begin{array}{l}\text { Identify the interview process and receive } \\
\text { interview feedback prior to formal interviews }\end{array}$ \\
\hline & Job application skills & 6 & Find available jobs \\
\hline & Job application skills & 4 & Negotiate a job/contract \\
\hline & $\begin{array}{l}\text { Identification of } \\
\text { desired job }\end{array}$ & 39 & $\begin{array}{l}\text { Determine how to choose between urban and rural } \\
\text { location job }\end{array}$ \\
\hline & $\begin{array}{l}\text { Identification of } \\
\text { desired job }\end{array}$ & 36 & $\begin{array}{l}\text { Determine how to choose between academic and } \\
\text { community practice job }\end{array}$ \\
\hline & $\begin{array}{l}\text { Identification of } \\
\text { desired job }\end{array}$ & 16 & $\begin{array}{l}\text { Learn the differences between salary/payment } \\
\text { systems }\end{array}$ \\
\hline \multirow[t]{2}{*}{$\begin{array}{l}\text { Continuing } \\
\text { Professional } \\
\text { Development }\end{array}$} & $\begin{array}{l}\text { Continuous } \\
\text { professional } \\
\text { education }\end{array}$ & 19 & $\begin{array}{l}\text { Identify learning needs in clinical practice and } \\
\text { create personal learning plan }\end{array}$ \\
\hline & $\begin{array}{l}\text { Professional bodies } \\
\text { and memberships }\end{array}$ & 24 & $\begin{array}{l}\text { Resources for licensing, education, and } \\
\text { professional associations }\end{array}$ \\
\hline \multirow{6}{*}{$\begin{array}{l}\text { Expectations } \\
\text { of } \\
\text { Profession }\end{array}$} & Medicolegal & 10,12 & $\begin{array}{l}\text { Learn and to demonstrate best practice for } \\
\text { effective documentation }\end{array}$ \\
\hline & Medicolegal & 10,33 & Learn local reporting obligations \\
\hline & Medicolegal & 35 & Demonstrate best practice for informed consent \\
\hline & Professional conduct & 29 & $\begin{array}{l}\text { Learn and demonstrate best practice for social } \\
\text { media use }\end{array}$ \\
\hline & Professional conduct & 40 & Describe the importance of collegiality \\
\hline & Professional conduct & 26 & $\begin{array}{l}\text { Demonstrate effective methods to presenting to } \\
\text { the public }\end{array}$ \\
\hline
\end{tabular}


Professional conduct $27 \quad$ Describe and demonstrate effective methods of advocacy

Quality Improvement $\quad 25 \quad$ Identify and analyze system level safety in practice

Teaching/supervising $11 \quad$ Demonstrate how to be an effective teacher, and role how to provide effective feedback to learners

$\begin{array}{llll}\begin{array}{l}\text { Practice } \\ \text { Management }\end{array} & \text { Practice finances } 3,2 \text { Demonstrate competence at billing and coding }\end{array}$

\begin{tabular}{|c|c|c|c|}
\hline & Practice finances & 3,20 & Identify financial aspects of managing a practice \\
\hline & $\begin{array}{l}\text { Strategy for learning } \\
\text { in TTP }\end{array}$ & 9,15 & $\begin{array}{l}\text { Greater autonomy during residency with resident- } \\
\text { run clinics }\end{array}$ \\
\hline \multirow[t]{2}{*}{$\begin{array}{l}\text { Life, Health } \\
\text { and Well- } \\
\text { being }\end{array}$} & Money & 5,13 & $\begin{array}{l}\text { Develop a personal financial plan, including } \\
\text { understanding of debt management/life,health } \\
\text { and disability insurance, and incorporation }\end{array}$ \\
\hline & Person & 7 & $\begin{array}{l}\text { Develop a personal and professional priority and } \\
\text { action plan, for work-life balance }\end{array}$ \\
\hline \multirow[t]{8}{*}{ Clinical Skills } & & 30 & $\begin{array}{l}\text { Learn and demonstrate best practice for patient } \\
\text { signovers }\end{array}$ \\
\hline & & 18 & $\begin{array}{l}\text { Demonstrate effective communication with } \\
\text { colleagues }\end{array}$ \\
\hline & & 21,37 & $\begin{array}{l}\text { Demonstrate understanding of the roles of } \\
\text { members of the multidisciplinary team, } \\
\text { demonstrate understanding of their role in } \\
\text { transitioning patients safely into community care }\end{array}$ \\
\hline & & 31 & Identify common techniques for conflict resolution \\
\hline & & 32 & $\begin{array}{l}\text { Demonstrate best practice for breaking bad news } \\
\text { to patients }\end{array}$ \\
\hline & & 34 & $\begin{array}{l}\text { Demonstrate strategies for managing challenging } \\
\text { family members }\end{array}$ \\
\hline & & 38 & $\begin{array}{l}\text { Demonstrate best practice for difficult patient } \\
\text { conversations }\end{array}$ \\
\hline & & 28,21 & $\begin{array}{l}\text { Demonstrate understanding of available } \\
\text { outpatient patient resources }\end{array}$ \\
\hline
\end{tabular}

\section{Figures}




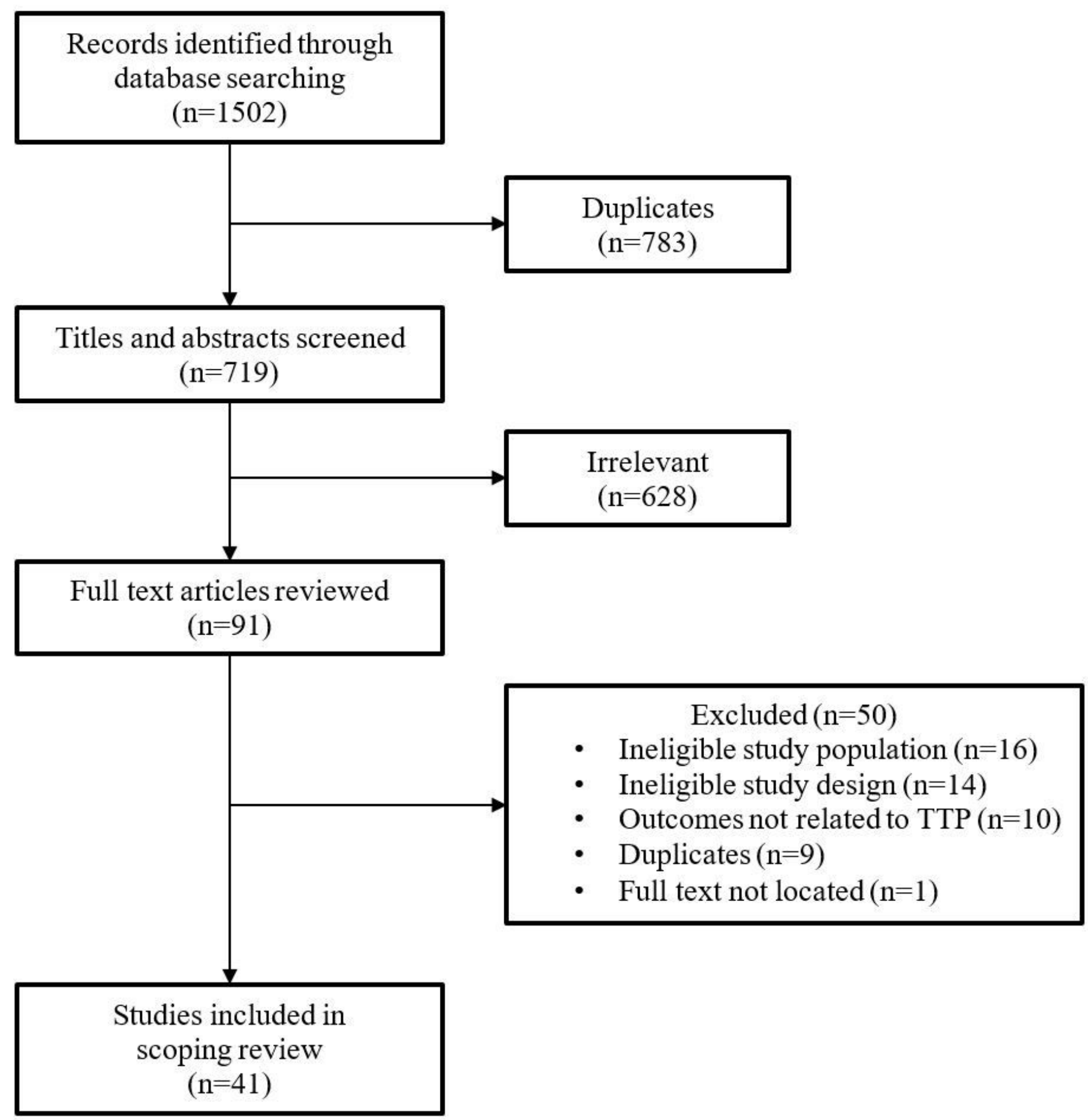

Figure 1

PRISMA diagram for included studies

\section{Supplementary Files}

This is a list of supplementary files associated with this preprint. Click to download. 
- BMCMedEdPaperFeb12SupplementaryTable1.docx

- BMCMedEdPaperFeb12VSupplementaryTable2.docx

- BMCMedEdPaperFeb12Appendix1.docx 